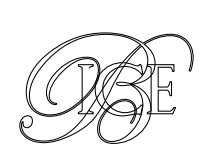

\title{
EL NUEVO SIGLO Y LA ENTRADA EN LA OMC VISIÓN DESDE LA OFICINA EN PEKÍN
}

\section{Un breve vistazo a China entre 2002 y 2018}

Mi primera visita a China se produjo en marzo de 2002, y lo que allí vi, y lo que me contaron los compañeros que entonces estaban allí destinados, fue determinante para revitalizar el interés latente que ya tenía por ese país y ese mercado, y para que unos meses después solicitara plaza en la Oficina Económica y Comercial en Pekín, la cual obtuve. Allí me incorporé ese mes de agosto, en la grata compañía del añorado Luis Cacho, nuevo consejero jefe.

En los años previos, el Gobierno reformista de Zhu Rongji había acometido valientes medidas, tales como la reestructuración de las empresas estatales, la privatización de la vivienda $\mathrm{u}$ otras orientadas a la accesión de China a la Organización Mundial de Comercio, que se produjo justo a finales de 2001. Estas reformas, comentadas con mayor detalle en otras partes de este número, sentaron las bases para la fascinante expansión económica de los años siguientes, basada sobre todo en la construcción (pareja a un proceso de urbanización sin

\footnotetext{
*Técnico Comercial y Economista del Estado.
} Versión de enero de 2018. precedentes, y que como es bien sabido arrastra a toda una serie de sectores industriales a ella vinculados) y en el comercio exterior a raíz de esa integración en la OMC. Si en 2001 la participación de China en las exportaciones mundiales apenas raspaba el 4 por 100, en 2008 se acercaba al 10 por 100 (y en 2016, al 14 por 100). Esa expansión económica, además, fue a un ritmo creciente durante el periodo previo a la crisis financiera internacional, hasta alcanzar en 2007 tasas de crecimiento (ireal!) del PIB superiores al 14 por 100 anual, y todo ello a pesar de que no eran pocas las voces que desde Occidente alertaban sobre el inminente colapso de China, debido a la morosidad en el sistema financiero, a su incapacidad de competir con los productos importados o a múltiples otras causas. Esos años de fuerte crecimiento tuvieron variadas consecuencias:

- Acelerado crecimiento de la renta disponible de las economías domésticas, y por tanto de la demanda de consumo, y cambio radical en los patrones de dicho consumo.

- Las altas tasas de crecimiento (hasta el doble del objetivo marcado en el Plan Quinquenal), y la creación de «bancos $\triangleright$ 
malos", terminaron por diluir las amenazas que pesaban sobre el sistema financiero.

- El crecimiento de la productividad, por encima del de los salarios (que aun así crecían fuertemente), favorecía la competitividad de las empresas chinas, tanto doméstica como internacional. Las exportaciones, y las reservas de divisas, batían récords año tras año.

- Las empresas chinas comenzaron a salir al exterior. Inicialmente, adquiriendo derechos sobre recursos naturales, de cara a asegurarse suministros necesarios para su desarrollo industrial, pero ya a mediados de la primera década del siglo también empezaron a invertir en tecnología y en marcas (las primeras operaciones relevantes fueron la compra de Thomson por TCL y la división de los $P C$ de IBM por Lenovo).

- Renovado interés de empresas extranjeras por invertir en China, en unos casos con la intención de aprovechar la estructura de costes para ensamblar componentes y materias primas para la reexportación (como fue el caso de muchas empresas de otros países asiáticos), y en otros para intentar acceder a ese dinámico mercado interno.

- Cambio de prioridades en la política económica: la Administración de la «tercera generación» de líderes, con el presidente $\mathrm{Hu}$ Jintao y el primer ministro Wen Jiabao, en ese contexto de fuerte crecimiento, perdió buena parte del apetito reformista del Gobierno Zhu. Se apostó por el rescate a la banca, la necesaria construcción de una red nacional de previsión social (tras ser desmanteladas las correspondientes a las empresas estatales) y, tras el impacto de la crisis financiera de 2008, por paquetes de estímulo basados en la inversión pública en infraestructuras.

Fueron años de transformación radical de la economía, de la sociedad, del paisaje urbano y de la propia percepción por parte de los ciudadanos chinos. Tras la trágica pausa ocasionada por el brote epidémico de SARS en la primavera de 2003, pronto se recuperó el ambiente de optimismo sobre el futuro. Y quienes allí vivíamos, de un modo u otro, y a pesar de todas nuestras reticencias, necesariamente nos contagiábamos de ese optimismo y de la excitación de saber que el mundo estaba cambiando ante nuestros ojos.

En verano de 2007, agotado el plazo máximo de estancia en el puesto, regresé a España, debo decir que con cierta nostalgia. Seguí visitando China por motivos de trabajo, tanto Pekín como Shanghai o Guangzhou, pero es preciso admitir que esas visitas ocasionales no son suficientes para seguir el pulso de un entorno tan dinámico. En algún momento entre los años 2007 y 2010 se pasó el punto de inflexión. Ese fue el intervalo en el cual, por una parte, se desató la crisis financiera en Occidente, con el consiguiente protagonismo de los paquetes de estímulo chinos en la recuperación global (según Christine Lagarde), y, por otra, se produjeron los dos acontecimientos que visibilizaban la «puesta de largo» de China como potencia recuperada tras siglo y medio de postergación: los Juegos Olímpicos de 2008, en Pekín, y la Expo de Shanghai en 2010.

Aunque no figuraba en mis planes, en 2010 se presentó la posibilidad de regresar a Pekín, en esta ocasión como consejero jefe de la Oficina, y obtuve la plaza, a la que me incorporé a primeros de diciembre de $D$ 
ese año, hasta agosto de 2016. La ciudad y el país que me encontré habían cambiado profundamente, como correspondía tras varios años de crecimiento acelerado: nuevas infraestructuras (metros, aeropuertos, líneas ferroviarias de alta velocidad, autopistas y un largo etcétera), edificios relucientes y urbanizaciones con todo tipo de servicios, un parque automóvil propio del primer mundo, centros comerciales repletos de las mejores marcas de lujo o una amplísima oferta gastronómica y cultural. Pero no todos los cambios eran positivos. El propio crecimiento económico y de las rentas había convertido la que era una ciudad asequible en una muy cara. El deterioro ambiental tras años de desarrollo industrial era notorio, no solo en lo más evidente, la polución del aire de Pekín, sino en todos los ámbitos. Los atascos de tráfico no eran nuevos, dada la trama urbana de la ciudad (ya en 2003 impresionaron a los jugadores del Real Madrid en su primera visita), pero el vertiginoso incremento en el número de vehículos privados los había hecho ya imposibles. Y por el lado de las percepciones, a los occidentales, y sobre todo a los europeos, se nos había dejado de ver como portadores de tecnologías avanzadas, y ahora éramos más bien los representantes de un orden caduco y de unos países en declive. Habíamos pasado a ser, como me decía un amigo británico, los nouveaux pauvres!

En los años que siguieron, China volvió a reinventarse a sí misma: ese modelo de crecimiento acelerado basado en la demanda externa, en la inversión en capital fijo, en costes laborales unitarios contenidos y en la represión financiera que canalizaba los ahorros de las familias hacia grandes empresas estatales que empleaban esa financiación en la inversión, ya fue definido en 2007 por el entonces primer ministro Wen Jiabao como «inestable, desequilibrado, descoordinado y, en última instancia, insostenible». Sin embargo, la inercia continuaba, y el necesario ajuste se pospuso con el megapaquete de estímulo lanzado a finales de 2008 (4 billones de RMB, unos 586.000 millones de USD) para paliar los efectos que China temía sufrir por la crisis financiera internacional y el desplome en la demanda exterior. Ese paquete logró que se mantuvieran altas tasas de crecimiento, pero retardó el «reequilibrio» a un nuevo modelo, de crecimiento más pausado, y más apoyado en el consumo doméstico, el valor añadido y la innovación. Además, al canalizarse a través de créditos a Gobiernos locales para inversiones en infraestructuras y a empresas estatales para que expandieran su capacidad en los sectores relacionados, como acero, cemento, cristal, etcétera, agravó los problemas de apalancamiento, de riesgo sistémico en el sistema financiero y de exceso de capacidad en muchos de esos sectores y empresas.

De modo que, acabado el impacto de ese estímulo, a partir de 2012 inevitablemente comenzaba el reequilibrio: el crecimiento se moderaba, los costes laborales unitarios crecían (en buena parte por razones demográficas, pese a ese crecimiento más lento, el número de entrantes al mercado laboral había pasado ya su pico, como resultado de años de política de control de la natalidad), la construcción y los sectores afines en la industria pesada se frenaban, las nuevas tecnologías se expandían, dando lugar al mayor y más dinámico mercado del mundo en e-commerce. Por su parte, el comercio exterior también decaía (debido a la débil recuperación de la demanda internacional, y a la caída en los precios de las materias primas, motivada en parte, precisamente, por la desaceleración $\triangleright$ 
industrial en China) y, en conjunto, crecía la importancia del consumo doméstico frente a la inversión, por el lado de la demanda, y de los servicios frente a la industria, por el lado de la oferta. Por otra parte, las empresas chinas abandonaban el cómodo papel pasivo en los mercados internacionales e intensificaban su actividad internacional. Todos estos cambios se concretaron a nivel oficial en la decisión del Tercer Pleno del Comité Central del Partido Comunista, en noviembre de 2013, que, por primera vez, mencionaba el «papel decisivo» que debía jugar el mercado.

Esa decisión generó expectativas de que se produjera, tras la década de complacencia del tándem Hu-Wen, un nuevo impulso a las reformas económicas, en áreas críticas como las empresas estatales o la liberalización de los sectores de servicios. Sin embargo, y pese a bien publicitadas iniciativas, como las zonas piloto de libre comercio, o algunos casos de propiedad mixta de empresas, los progresos reales han sido escasos. En los últimos meses, y al margen de las declaraciones de Xi Jinping en Davos, proponiéndose como nuevo paladín del libre comercio, la prioridad se centró más en la estabilidad, de cara al crucial Congreso del partido del pasado otoño, en el que el propio Xi afianzó su poder. Adicionalmente, y ante la ya elevada tasa de endeudamiento de empresas y entidades locales, se identificó un nuevo motor económico en las economías domésticas: una agresiva política de facilitación y abaratamiento de los préstamos hipotecarios consiguió relanzar el sector inmobiliario, y los muchos otros con él relacionados, contribuyendo a alcanzar, o incluso superar, los objetivos fijados de crecimiento. En todo caso, las tendencias en la construcción residencial parecen apuntar hacia un agotamiento paulatino de este motor, por lo que resulta probable que afloren de nuevo los desafíos derivados del necesario cambio de modelo y el crecimiento sea algo menor (aunque aún muy rápido).

Pese a la indudable capacidad de China para adaptarse a nuevas situaciones, desmintiendo repetidamente a los escépticos que llevan treinta años prediciendo un colapso inminente, los desafíos son reales: dudosas seguridad jurídica y fiabilidad del marco institucional; sistema fiscal subdesarrollado e ineficiente división del mismo entre niveles de la Administración; excesiva dependencia de la banca estatal; un sector de empresas estatales inflado y poco productivo, que lastra a la parte más dinámica de la economía; una pirámide demográfica en proceso de brusca transformación; proteccionismo no solo nacional, sino también local; o una severa degradación ambiental, aún pendiente a pesar de los innegables progresos en la expansión de las energías renovables. De la manera en que se afronten estos problemas dependerá en buena medida el futuro curso de China y su capacidad para evadir la middleincome trap.

\section{La actividad de las empresas españolas}

En el periodo del boom del crecimiento en China, entre 2001 y 2007 , es cuando se desarrolla una apuesta más decidida por China por parte de las empresas españolas. Crece en esa época la presencia de empresas enfocadas en fabricar en China para vender en España, o en general en Europa, bienes de consumo, electrodomésticos o materiales de construcción, así como componentes de los mismos para incorporarlos al producto final de empresas chinas exportadoras. También se instalan multitud de pequeñas $\triangleright$ 
empresas de consultoría, trading o sourcing, dedicadas a la búsqueda de proveedores chinos para importadores españoles, generalmente de esos mismos productos y sectores. Hubo años en que eran varios miles los visitantes españoles a la Feria de Cantón, el gran escaparate de producto chino para la exportación.

Otras empresas españolas se implantaron en China para producir para el mercado doméstico, como, por ejemplo, las de componentes de automoción (en muchos casos a instancias de sus clientes multinacionales, que veían cómo su producción en China crecía continuamente), algunas de maquinaria para abastecer un mercado en que la inversión en capital fijo crecía a ritmos vertiginosos, o las de energías renovables, aunque con suerte dispar según sus expectativas y la política de implantación seleccionada. A todas estas empresas les acompañaron empresas de servicios, como los despachos de abogados, siguiendo a sus clientes, o los bancos y cajas de ahorros, buscando ofrecer financiación a un comercio bilateral en claro ascenso. Algún banco, como alguna empresa de telecomunicaciones, tomó participaciones, necesariamente minoritarias debido a las restricciones de la legislación china, en empresas locales, como apuesta a largo plazo y alianza estratégica. Empresas de moda y calzado también aprovecharon el desarrollo de China y el incremento de renta disponible de sus economías domésticas. Por otra parte, se comenzaron a cumplir algunos de los compromisos adquiridos en el proceso de accesión a la OMC, firmándose el protocolo bilateral de cítricos en 2005 y el de porcino en 2007, con lo que nuestras empresas empezaron a exportar estos productos, particularmente carne y despojos de porcino, en cantidades importantes y crecientes.
El número de empresas españolas presentes en China se disparó, de unas 120 a más de 600. El de empresas exportadoras se multiplicó por cinco en una década, de unas 1.700 en 2000 a 6.500 en 2010, en todos los sectores, pero especialmente en bebidas (son los años en que el consumo de vino se convierte en un signo de distinción). Las exportaciones totales vivieron una evolución similar, pasando de 550 millones de euros en 2000 a más de 2.600 en 2010, con mayor ritmo en este caso en productos industriales. También por cinco se multiplicó el número de empresas importadoras de producto chino, de menos de 10.000 a casi 50.000 , pero, mientras que en el año 2000 había más empresas importando bienes de consumo, en 2010 ya eran más las que importaban productos industriales, muestra de la propia evolución del tejido industrial chino, que se iba desarrollando, más allá de los sectores tradicionales, más intensivos en mano de obra, como textil, calzado, juguete o revestimientos cerámicos. Las importaciones totales también crecieron, de unos 5.000 millones de euros en 2000 a más de 20.000 en 2008. Ese crecimiento, asimismo, fue a un ritmo superior a la media en el caso de determinados productos industriales, como electrónica, informática o telecomunicaciones. Algunos productos, como los paneles solares chinos, en algún año llegaron a superar por sí solos el total de las exportaciones españolas a China.

En cuanto al nuevo escenario que se abrió a partir de la crisis financiera en Occidente, y del incipiente cambio de modelo en China, nuestras empresas han ido adaptando su actividad a las nuevas circunstancias: modelos de negocio que hacía pocos años eran muy rentables dejaron de serlo y aparecieron nuevas oportunidades, antes no consideradas. Así, empresas que se habían establecido en $\triangleright$ 
China para aprovechar mano de obra barata, y contando con los mercados desarrollados en expansión permanente, se encontraron con que los costes al alza, y la crisis, y posterior débil recuperación, en esos mercados, hacían inviable su continuidad. También muchas de las pequeñas consultoras de sourcing tuvieron que dejar de operar. Otras empresas supieron reorientar su actividad y aprovechar la experiencia y los contactos obtenidos para buscar nuevas áreas de negocio, como, por ejemplo, colaborar con empresas chinas en mercados terceros o incursionar en nuevos sectores que (paulatinamente) se iban abriendo a la inversión extranjera. Por otra parte, cada vez eran más las grandes empresas del sector servicios que buscaban oportunidades emergentes. Las empresas más orientadas al consumo doméstico, como las de moda, o las de componentes de automoción, incrementaron su presencia, y aparecieron nuevos sectores, como el aeronáutico, en los que nuestras empresas tenían mucho que aportar. El número absoluto de empresas españolas implantadas en China probablemente no haya variado mucho, pero sí lo ha hecho su composición, y también el tipo de actividad de las empresas que continúan presentes.

Por el lado de las exportaciones, el cambio más significativo se produjo a partir de 2011 , año en el que, ante las consecuencias de la crisis y la débil recuperación de su mercado doméstico, más y más empresas españolas comenzaron a mirar al exterior, especialmente a China. En ese año, la cifra de empresas que exportaron a China se incrementó con respecto al año anterior nada menos que en un 73 por 100 , de 6.586 a 11.386 (el número total de exportadores a todo el mundo también aumentó, pero mucho menos, un 13 por 100), y ha continuado creciendo hasta las más de
15.000 de 2016. También significativo es que el número de exportadores regulares haya aumentado desde menos de 2.000 hasta más de 5.000 (algo aún más reciente, concentrado en los últimos tres o cuatro años), lo cual muestra que el mercado chino se ha convertido en habitual para esas empresas, que ya lo han integrado en su estrategia de forma permanente y no solo de manera ocasional. Especialmente dinámicos se muestran sectores como automoción, alimentos y bebidas (por el cambio en la dieta y por las preocupaciones en torno a la seguridad alimentaria), moda, TIC (aunque desde una base limitada) o todo lo relacionado con el cuidado de la salud, como la farmaquímica. Se espera que la conclusión de nuevos protocolos sanitarios (carne de ave, uva de mesa) permita ampliar la gama de alimentos exportados por nuestras empresas. La expansión del comercio electrónico B2C transfronterizo abre oportunidades a pymes de sectores de consumo que no cuentan con presencia física en China. Por contra, los productos que más sufren son los que habían venido suministrando equipos y materias primas a sectores chinos que han desarrollado excesos de capacidad, como, por ejemplo, las semimanufacturas metálicas.

Como resultado de todo ello, China es ya (pese a la distancia, al relativo desconocimiento y a los múltiples obstáculos que aún existen) el tercer mercado fuera de Europa para las empresas españolas y el quinto de todo el mundo al que mayor número de compañías exportan mercancías.

La recuperación de la economía española tuvo otras consecuencias. A partir de 2013, y tras superar titubeos previos, debidos a la incertidumbre sobre la zona euro, y a la expectativa de mayores bajadas en los precios de los activos, España entró de lleno en el punto $\triangleright$ 


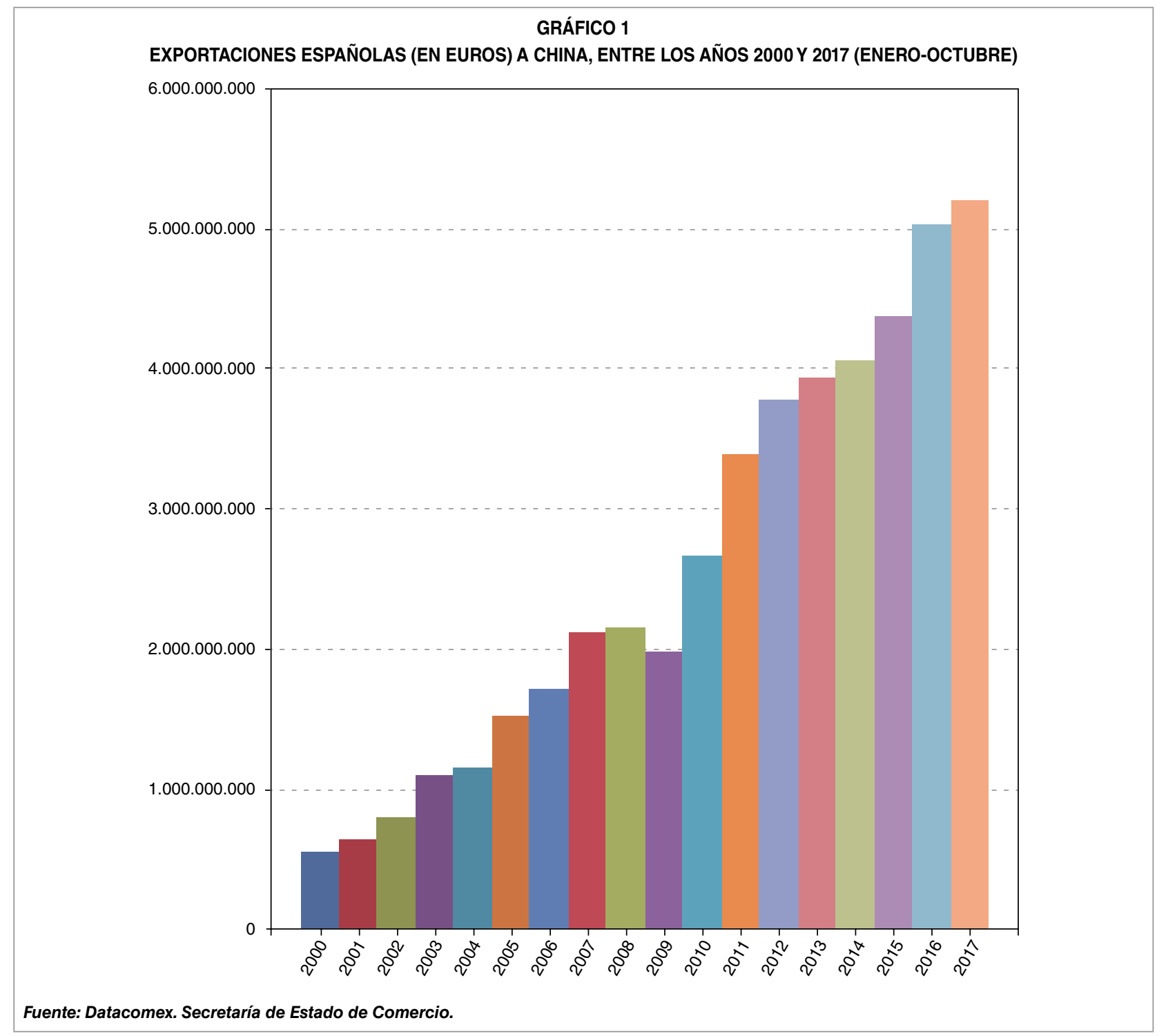

de mira de los inversores chinos. Las primeras operaciones se concentraban en pocos sectores, el agroindustrial y el turístico-inmobiliario, aparte del deportivo, pero esto también ha ido evolucionando. Las motivaciones prioritarias de los inversores chinos en el exterior (acceder a productos, tecnologías y marcas que les sirvan para competir en el propio mercado doméstico chino, o buscar complementariedades que les ayuden en su operativa internacional) les han llevado a identificar oportunidades en otros sectores, como la ingeniería, los servicios urbanos o la aeronáutica.

\section{La actividad de la Oficina Comercial en Pekín}

La Oficina Comercial en Pekín ha sido, en todo este periodo, una de las oficinas con una panoplia más amplia de actividades en toda la red: gestión de barreras comerciales, relaciones institucionales bilaterales, gestión de instrumentos financieros, un intenso calendario de actividades de promoción comercial de todo tipo (ferias, misiones, catas, degustaciones, concursos, acuerdos con plataformas de comercio electrónico, cuentas en redes $D$ 
Javier Serra

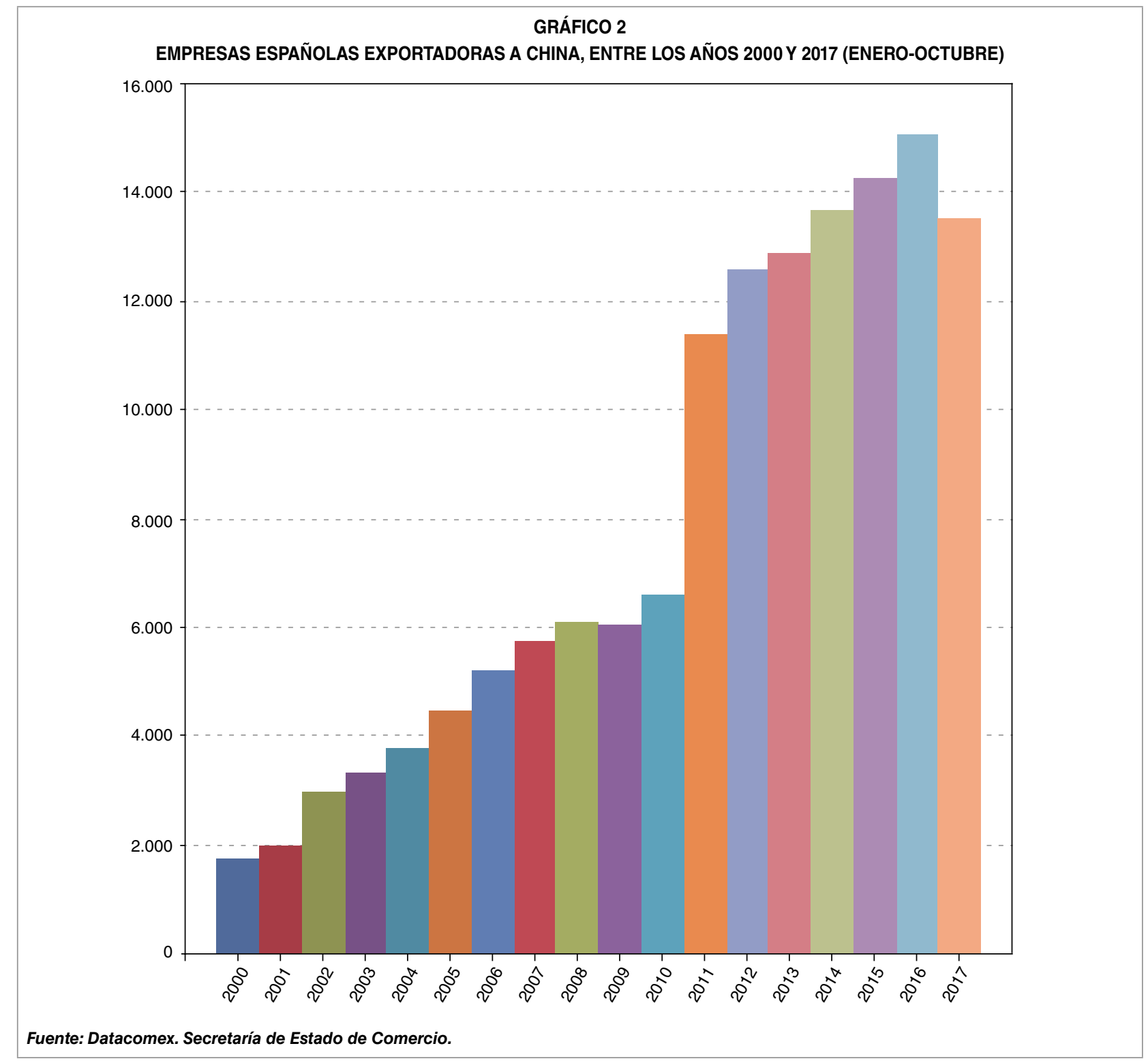

sociales chinas), información económica, elaboración de estudios, notas y guías, atención a consultas y servicios personalizados a empresas, captación de inversiones chinas, atención a inversores españoles, y, ya más recientemente, relaciones con instituciones financieras multilaterales (en particular, con el nuevo Banco Asiático de Inversiones en Infraestructuras), y atención a proyectos conjuntos en mercados terceros. Obviamente, el interés creciente de las empresas españolas por China, ya descrito, y cuantificado, implicaba una carga de trabajo también creciente, que no necesariamente se acompasaba con la disponibilidad de recursos.

En términos generales, la Oficina en Pekín, como las otras en China (nuestros compañeros en Shanghai y, más adelante, también en Cantón, con los que siempre tuve el placer de trabajar en estrecha colaboración), y como es su cometido, acompañó y, en la medida de lo posible, guio a las empresas españolas interesadas en el mercado a todo lo largo de las transformaciones arriba descritas, procurando ayudarlas a aprovechar las oportunidades y $\triangleright$ 
GRÁFICO 3

EMPRESAS ESPAÑOLAS EXPORTADORAS A CHINA DE MANERA REGULAR, ENTRE LOS AÑOS 2003 Y 2017 (ENERO-OCTUBRE)

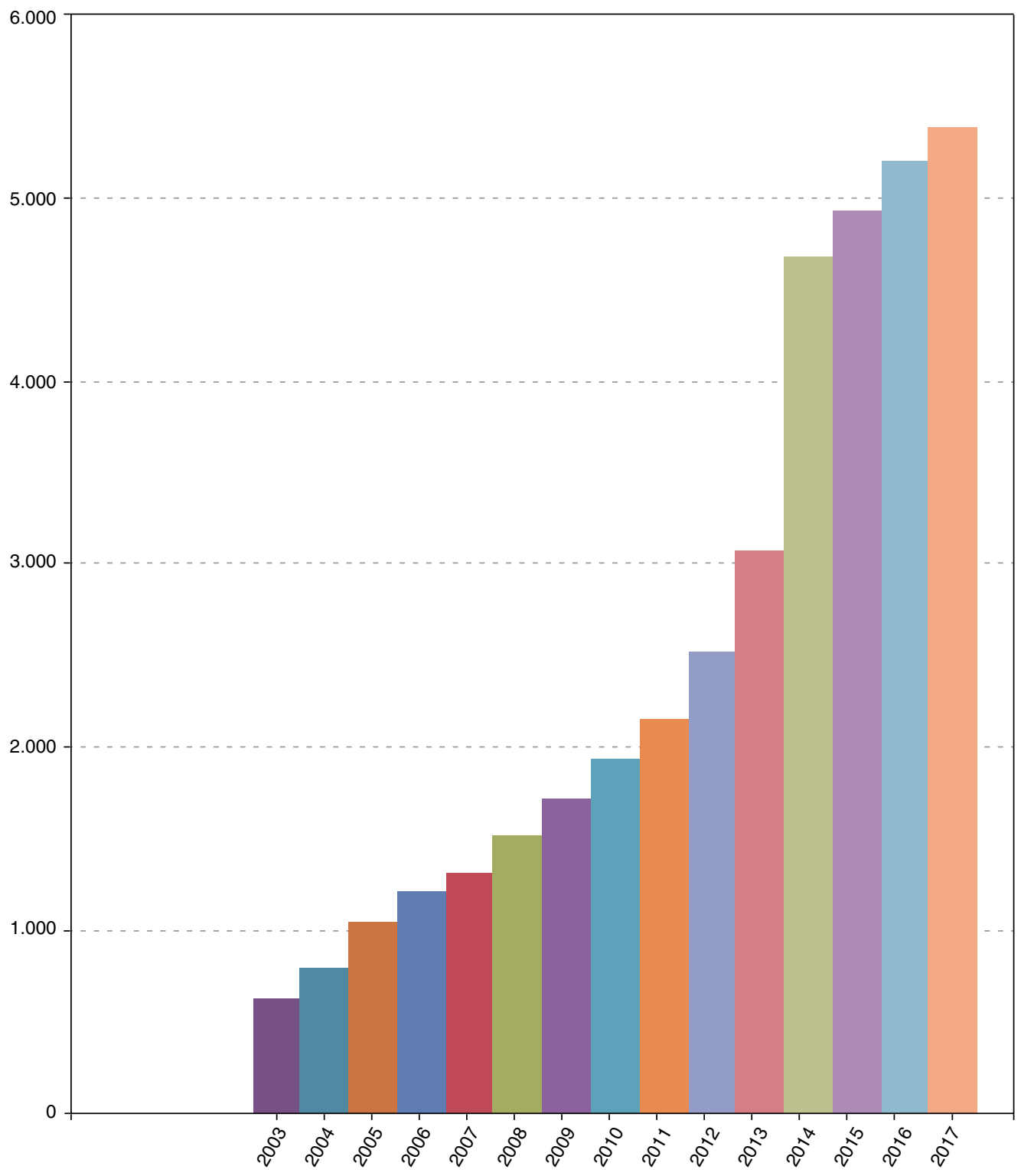

Fuente: Datacomex. Secretaría de Estado de Comercio.

evitar los riesgos que de esa situación se iban derivando. Esto, en ocasiones, implicaba una labor disuasoria, deshaciendo expectativas irreales sobre el mercado, o sobre las condiciones de operación en el mismo. Esto se hacía siempre con el objetivo de beneficiar a las empresas españolas, no ya incrementando sus ingresos, sino al menos evitando que incurrieran en costes de imposible recuperación.
En un país como China, el aspecto institucional sigue teniendo un papel destacado, y corresponde a la Oficina en Pekín su seguimiento y relación con las autoridades centrales del Gobierno chino. Además, como corresponde al tamaño y dinamismo del mercado, China ha sido sistemáticamente un país prioritario para las autoridades españolas. Así, y en el marco de las Comisiones Mixtas, ahora anuales, $D$ 
hay desde noviembre de 2015 un Grupo de Trabajo sobre inversiones bilaterales, y se está creando un Consejo Asesor Empresarial, formado por las empresas más relevantes de cada país con intereses en el otro, con capacidad de elevar recomendaciones y propuestas a ambos Gobiernos. También se está colaborando para articular mecanismos que favorezcan la cooperación de empresas españolas y chinas en mercados terceros. No cabe ignorar que un uso eficaz de estas relaciones institucionales ha permitido en varios casos relevantes solucionar contenciosos específicos que afectaban a diversas empresas españolas.

Por lo que se refiere a la remoción de barreras para el acceso de distintos productos o servicios al mercado chino, hasta que se abrió la Consejería de Agricultura en Pekín en 2009, fue la Oficina Comercial la interlocutora con las autoridades chinas, tanto para el protocolo de cítricos (firmado en 2005) como para el de porcino (2007) o el certificado de cosméticos. Posteriormente siguió activa en estos aspectos, ya en coordinación con la Consejería de Agricultura (para la consecución de nuevos protocolos, como el de caballos vivos, el de alfalfa o el de fruta de hueso) o con la Delegación de la UE, trasladando las prioridades de nuestras empresas e informando a las mismas sobre las novedades que se iban produciendo.

Otro aspecto de la actividad institucional es el seguimiento de los posibles contenciosos comerciales. La multiplicación de la cuota china en las exportaciones mundiales por un factor superior a tres (con el simétrico declive en las de los principales países, con la destacada excepción de España, por cierto), junto con acusaciones de ayudas públicas a sus empresas y prácticas no competitivas para volcar en los mercados internacionales el exceso de capacidad en multitud de sectores, han originado fuertes tensiones. Procedimientos antidumping y antisubvención por parte de la UE frente a productos chinos han sido respondidos en ocasiones con medidas similares en sentido contrario. Así, y por poner un ejemplo entre muchos, los procedimientos frente a los paneles solares y a los equipos de telecomunicaciones chinos tuvieron como reflejo el inicio de investigaciones sobre las exportaciones de vino europeo a China, con un duro efecto potencial sobre más de un millar de exportadores españoles. Al final se llegó a una solución, pero todo el proceso requirió de una información constante, tanto a las autoridades españolas como a nuestras empresas.

En la primera década del milenio, la cooperación financiera, que tan importante había sido en las relaciones económicas y comerciales (primero FAD, luego FIEM), se mantuvo, aunque su peso dentro de las relaciones bilaterales iba disminuyendo progresivamente, hasta que China alcanzó en 2012 el nivel de renta per cápita que la excluía de la elegibilidad para financiación concesional ligada. Por otra parte, según las empresas chinas iban dominando diferentes tecnologías y el país reducía su dependencia de la financiación exterior, nuestros créditos oficiales se aplicaban cada vez menos a proyectos integrales llave en mano, sino más bien a determinadas partes, o nichos, de proyectos, como catenarias o ticketing en proyectos ferroviarios o de metro.

A medida que disminuía la importancia de estos créditos, crecía la de otros instrumentos de apoyo, como la elaboración de información fidedigna, el respaldo ante las autoridades locales o la promoción comercial y la generación de espacios de encuentro entre empresas españolas y chinas.

Un elemento de competitividad de gran relevancia en los negocios, y especialmente en $D$ 
los internacionales, es contar con información veraz, actualizada e independiente sobre el mercado, y, especialmente, sobre la competencia, tanto internacional como local, a la hora de tomar decisiones estratégicas. Esto, que es así en todas partes, en el caso de China además es particularmente difícil, por el menor acceso a la información y por la propia velocidad en su evolución. Este elemento afecta especialmente a dos aspectos de la operativa de las empresas internacionales en China. En primer lugar, la fijación de unas expectativas ajustadas a la situación del mercado, ya que, desgraciadamente en muchos casos, expectativas excesivamente optimistas (o pesimistas) impiden a las empresas formular estrategias adecuadas. $\mathrm{Y}$, en segundo lugar, a veces se constata un exceso de confianza en la información trasladada por interlocutores interesados. Esto ocurre a veces, tanto con los socios comerciales sobre el terreno (cuya selección es absolutamente crítica) como con algunas autoridades locales que adquieren compromisos que no se corresponden con sus competencias, lo que hace que la empresa extranjera implicada incurra en gastos e inversiones en proyectos que, en última instancia, pueden terminar revelándose como no viables. Cuando eso ha ocurrido, la Oficina ha intentado minimizar los costes para la empresa española a través de su interlocución con las autoridades chinas.

Pero, además de suministrar información a empresas, la Oficina en Pekín, por su función bilateral, también tiene el mandato de informar a las propias autoridades españolas y de asesorarlas en la formulación de la estrategia en materia de relaciones económicas y comerciales. En el periodo aquí reseñado hubo dos aspectos que me gustaría destacar.

En primer lugar, complementar, y compensar, informaciones en ocasiones poco fundamentadas, difundidas en algunos medios internacionales sobre lo que estaba ocurriendo en la economía china. Así, en el verano de 2015 nos tocó aclarar cuál era entonces la representatividad en el conjunto de la economía de la Bolsa de Shanghai (menor a lo percibido desde fuera), que se acababa de desplomar, tras meses de subidas vertiginosas, así como explicar las causas y circunstancias reales de la depreciación que en fechas posteriores sufrió el RMB. Recuerdo bien cómo José Luis Kaiser y yo tuvimos que explicar que esos fenómenos no implicaban un inminente derrumbe de la economía china, aun cuando esta no estuviera exenta de problemas reales (que eran otros), como se ha indicado más arriba.

En segundo lugar, llamar la atención sobre el papel de China en las cadenas globales de valor y cómo esto hace recomendable adoptar una visión más global de las relaciones, más allá del estricto foco bilateral. Esto supone, al menos, dos implicaciones:

- Una perspectiva más amplia conduce a matizar la relevancia del (sin duda llamativo) déficit comercial bilateral. Si bien es cierto que dicho déficit es elevado, y que matemáticamente explica nuestro déficit global, no es este el caso conceptualmente, y resulta fácil que lleve a conclusiones incorrectas, o al menos incompletas. La integración industrial de Asia ha hecho que buena parte de ese déficit se derive de importaciones antes procedentes de otros países asiáticos (Japón, Corea, Taiwán), según las empresas de esos países iban trasladando su producción a China. Por eso mismo se reduce nuestro déficit con Japón, no porque desde allí se importe más producto español. Es decir, el déficit comercial $\square$ 
Javier Serra

lo es con el conjunto de Asia; de hecho, la participación en el total de nuestras importaciones de las procedentes de la suma de países de Lejano Oriente no se movió nada en diez años, desde 2005 hasta 2014, suponiendo en ambos años exactamente el mismo porcentaje, un 9,56 . $Y$ a pesar de todo, nuestra tasa de cobertura con China ha mejorado sustancialmente en estos últimos años, duplicándose holgadamente desde principios de siglo (Gráfico 4), evidencia de que desde la entrada de China en la OMC nuestras exportaciones hacia ese mercado han crecido mucho más que nuestras importaciones procedentes del mismo.

- Dada la competitividad y expansión internacional de las empresas chinas, conviene pasar de pensar solo en «hacer $D$

TASA DE COBERTURA EN EL COMERCIO ENTRE ESPAÑA Y CHINA, ENTRE LOS AÑOS 2000 Y 2017 (ENERO-OCTUBRE)

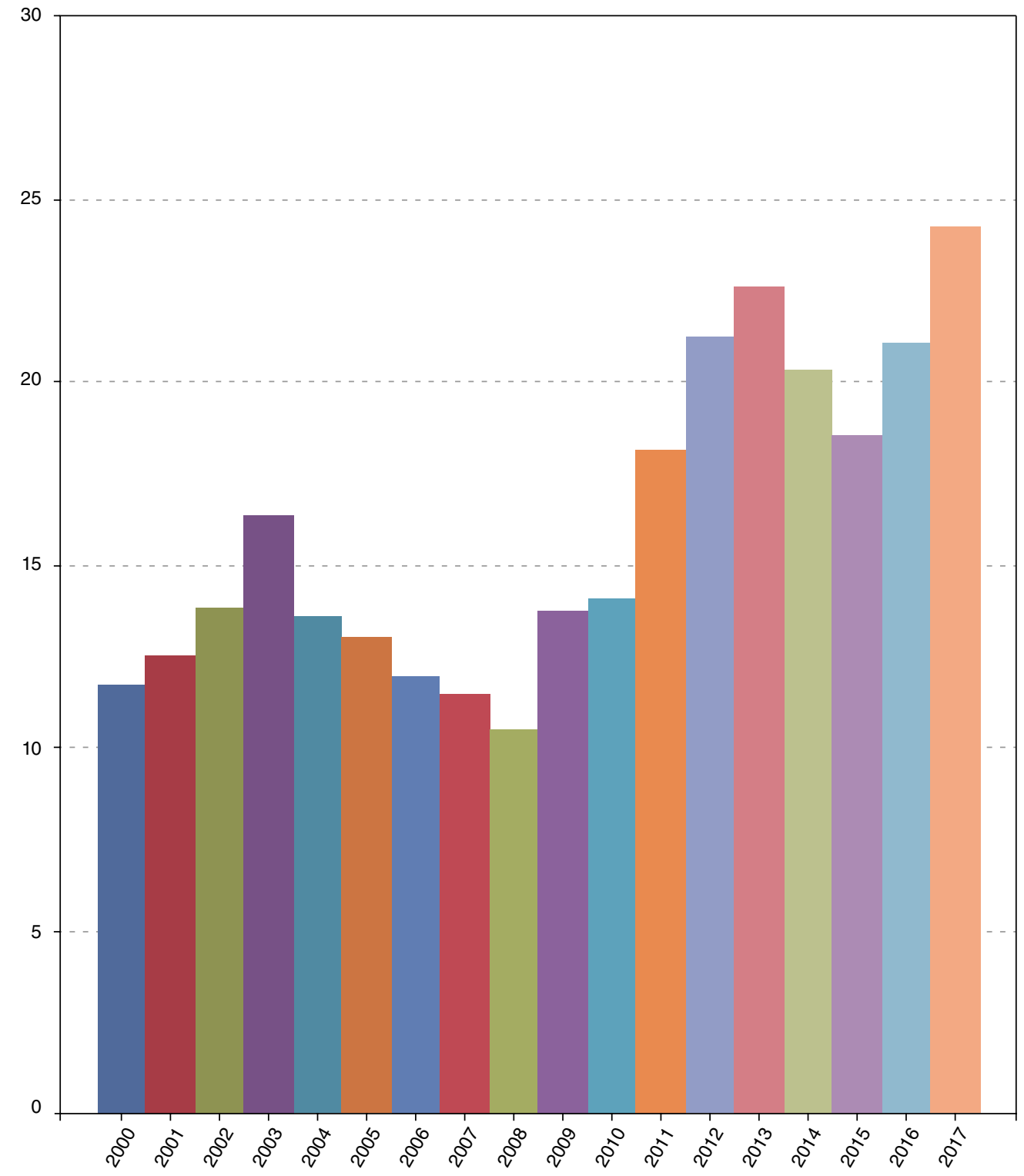

Fuente: Datacomex. Secretaría de Estado de Comercio. 
negocios EN China» a orientarse hacia «hacer negocios CON China», en cualquier lugar del mundo. Ya hay casos (que, por otra parte, y como es lógico, no afloran en ninguna estadística bilateral) de colaboración entre empresas de ambos países en mercados terceros, y, con la ambiciosa iniciativa china One Belt One Road, cabe prever que este tipo de operaciones se haga más frecuente en el próximo futuro, si se aprovechan las oportunidades que irán surgiendo, en particular en los sectores de infraestructuras.

Otra área de actividad de la Ofcome, iniciada ya antes, pero de particular importancia a partir de 2008-2009, ha sido la difusión de la realidad económica y tecnológica de España, ante autoridades, prescriptores y medios de comunicación chinos, con el objeto genérico de mejorar la imagen de nuestro país, nuestros productos, nuestras marcas y nuestras empresas, pero también con el más concreto de contribuir a fomentar el interés por parte de empresas chinas en invertir en España.

\section{Y de aquí en adelante, ¿qué cabe esperar?}

Las perspectivas a futuro estarán muy condicionadas por cómo evolucione el crecimiento chino (sobre esto sirvan mis comentarios anteriores) y su apertura a empresas extranjeras, en especial en sectores de servicios. Si se da una apertura significativa, sea a causa de la necesidad de impulsar esos sectores para mantener el crecimiento o por acuerdos internacionales (está en negociación precisamente el acuerdo bilateral de inversiones con la Unión Europea, en el que la parte europea desea incluir elementos de acceso mejorado al mercado chino), se abrirán grandes oportunidades para nuestras empresas más internacionalizadas, tal y como ocurrió (salvando las distancias, obvias) en América Latina en los años noventa. En todo caso, yo carezco de bola de cristal, y de lo único que puedo estar seguro es de que China nos continuará sorprendiendo, igual que, en diferentes momentos, sorprendió a María, a Enrique, a Coriseo, a mí mismo y a tantos otros. 

BOLETÍN ECONÓMICO DE INFORMACIÓN COMERCIAL ESPAÑOLA (BICE) ISSN 0214-8307

\section{SUSCRIPCIÓN ANUAL}

\begin{tabular}{|c|c|c|c|}
\hline & $\begin{array}{l}\text { ESPAÑA } \\
1 \text { año }\end{array}$ & $\begin{array}{c}\text { UNIÓN EUROPEA } \\
1 \text { año }\end{array}$ & $\begin{array}{c}\text { RESTO DEL } \\
\text { MUNDO } \\
1 \text { año }\end{array}$ \\
\hline SUSCRIPCIÓN & $65,00 €$ & $85,00 €$ & $85,00 €$ \\
\hline $\begin{array}{l}\text { Gastos de envío } \\
\text { España }\end{array}$ & $5,76 €$ & $24,36 €$ & $30,00 €$ \\
\hline $\begin{array}{l}\text { Más } 4 \% \text { de IVA. } \\
\text { Excepto Canarias, Ceuta y Melilla }\end{array}$ & $2,83 €$ & & \\
\hline TOTAL & $73,59 €$ & $109,36 €$ & $115,00 €$ \\
\hline
\end{tabular}

\section{EJEMPLARES SUELTOS}

\begin{tabular}{|c|c|c|c|}
\hline \multicolumn{4}{|c|}{ BOLETÍN ECONÓMICO DE INFORMACIÓN COMERCIAL ESPAÑOLA } \\
\hline & $\begin{array}{l}\text { ESPAÑA } \\
1 \text { ejemplar }\end{array}$ & $\begin{array}{l}\text { UNIÓN EUROPEA } \\
1 \text { ejemplar }\end{array}$ & $\begin{array}{c}\text { RESTO DEL } \\
\text { MUNDO } \\
1 \text { ejemplar }\end{array}$ \\
\hline NÚMERO SUELTO & $7,00 €$ & $9,00 €$ & $9,00 €$ \\
\hline $\begin{array}{l}\text { Gastos de envío } \\
\text { España }\end{array}$ & $0,48 €$ & $2,03 €$ & $2,50 €$ \\
\hline $\begin{array}{l}\text { Más } 4 \% \text { de IVA. } \\
\text { Excepto Canarias, Ceuta y Melilla }\end{array}$ & $0,30 €$ & & \\
\hline TOTAL & $7,78 €$ & $11,03 €$ & $11,50 €$ \\
\hline \multicolumn{4}{|c|}{ BOLETÍN ECONÓMICO DE INFORMACIÓN COMERCIAL ESPAÑOLA } \\
\hline & $\begin{array}{l}\text { ESPAÑA } \\
1 \text { ejemplar }\end{array}$ & $\begin{array}{l}\text { UNIÓN EUROPEA } \\
1 \text { ejemplar }\end{array}$ & $\begin{array}{l}\text { RESTO DEL } \\
\text { MUNDO } \\
1 \text { ejemplar }\end{array}$ \\
\hline $\begin{array}{l}\text { NÚMERO SUELTO } \\
\text { EXTRAORDINARIO }\end{array}$ & $12,00 €$ & $15,00 €$ & $15,00 €$ \\
\hline Gastos de envío España & $0,48 €$ & $2,03 €$ & $2,50 €$ \\
\hline $\begin{array}{l}\text { Más } 4 \% \text { de IVA. } \\
\text { Excepto Canarias, Ceuta y Melilla }\end{array}$ & $0,50 €$ & & \\
\hline TOTAL & $12,98 €$ & $17,03 €$ & $17,50 €$ \\
\hline
\end{tabular}

\section{DATOS}

Nombre y apellidos

Empresa

Domicilio

D.P.

N.I.F.

Teléf.

Email

\section{DATOS DEL EDITOR:}

NIF:S2800568D

Transferencia a la cuenta de ingresos por venta de publicaciones del Ministerio de Economía y Competitividad.

IBERCAJA. Calle Alcalá 29. 28014 MADRID (ESPAÑA) CÓDIGO CUENTA CLIENTE: 2085-9252-07-0330598330 CÓDIGO BIC DE IBERCAJA: CAZRES2Z

IBAN: ES47 2085-9252-07-0330598330

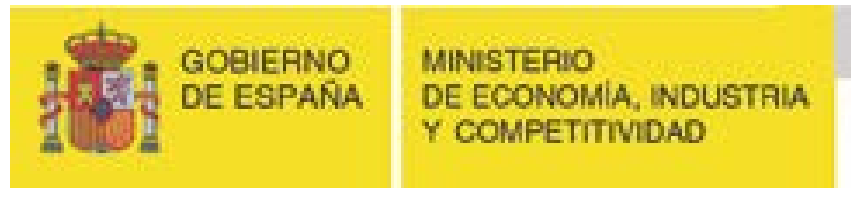

\section{SUESECAETARIA}

BECRETARIA GENERAL TECNICA

DUTCIRECCON GENTRML OE

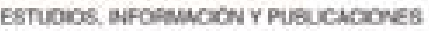

Suscripciones y ventas por correspondencia:

Paseo de la Castellana, $1628^{\text {a }}$ Planta 28046 Madrid. Teléfono 916037993 / 97

Suscripciones a través de la página web del Ministerio de Economía, Industria y Competitividad distribucionpublicaciones@mineco.es 


\section{NORMAS DE ESTILO DE PUBLICACIÓN}

La persona o personas interesadas en presentar un artículo para su publicación en el Boletín de Información Comercial Española (BICE) deberán enviar el artículo en formato Microsoft Word a la dirección de correo electrónico revistasice.sscc@comercio.mineco.es

El documento debe cumplir las siguientes características:

1. Ser material original no publicado ni presentado en otro medio de difusión.

2. La extensión total del trabajo (incluyendo cuadros, gráficos, tablas, notas, etcétera) no debe ser inferior a 15 páginas ni superior a 20. La fuente será Times New Roman, tamaño 12 y espaciado doble. Estar paginado en la parte inferior derecha de cada página.

3. En la primera página se hará constar el título del artículo que deberá ser breve, claro, preciso e informativo y la fecha de conclusión del mismo. Nombre y dos apellidos del autor o autores, filiación institucional, dirección, teléfono y correo electrónico de cada uno de ellos, así como la forma en que desean que sus datos aparezcan.

4. En la segunda página del texto se incluirá:

- El título.

- Un resumen del trabajo con una extensión máxima de 10 líneas con la siguiente estructura: objetivo, método y principal resultado o conclusión.

- De 2 a 6 palabras clave que no sean coincidentes con el título.

- De 1 a 5 códigos de materias del Journal of Economic Literature (clasificación JEL) para lo cual pueden acceder a la siguiente dirección electrónica:

https://www.aeaweb.org/jel/guide/jel.php

5. En las siguientes páginas se incluirán el texto, la información gráfica y la bibliografía con la siguiente organización.

- Se incluirá, por este orden, introducción, desarrollo, conclusiones y bibliografía y anexos si los hubiera. Los apartados y subapartados se numerarán en arábigos respondiendo a una sucesión continuada utilizando un punto para separar los niveles de división, según el siguiente modelo:

\section{Título del apartado}

\subsection{Título del apartado}

\subsubsection{Título del apartado}

\section{Título del apartado}

- Las notas de pie de página irán integradas en el texto y su contenido debe estar al final de su misma página en tamaño 10 y espacio sencillo.

- En un archivo Excel independiente se incluirá la representación gráfica (cuadros, gráficos, diagramas, figuras, etc.), que debe llevar título, estar numerada y referenciada en el texto.

En la parte inferior se incluirá la fuente de información y/o notas aclaratorias.

- Las citas de libros y artículos en el texto, se indicarán entre paréntesis con el apellido del autor y el año. Ej.: (Martínez, 1991).

- Las referencias a siglas deben ir acompañadas, en la primera ocasión en que se citen, de su significado completo.

- La bibliografía se ordenará alfabéticamente siguiendo las normas de la American Psychological Association (Harvard-APA): http://cibem.org/paginas/img/apa6.pdf

Libros

APELLIDOS, A.A. (año de publicación). Título del libro (edición) (volumen). Ciudad: Editorial.

Artículo en revista científica

APELLIDOS, A.A. (año de publicación). «Título del artículo». Título de la revista, volumen (número), números de páginas.

\section{Documento en línea}

APELLIDOS, A.A. u ORGANISMO (año, mes de publicación). Título, [en línea]. Ciudad: Editorial. Disponible en:

http://cenamb.rect.ucv.ve/siamaz/dicciona/canaima/canaima2.htm [Recuperado: 2000, 3 de junio]. 